\title{
A rigorous method to calculate the rising speed of gas kick
}

\author{
Kegang Ling $\cdot$ Jun $\mathrm{He} \cdot$ Jun Ge $\cdot$ Peng Pei $\cdot$ \\ Zheng Shen
}

Received: 16 February 2013/ Accepted: 24 February 2014/Published online: 17 March 2014

(c) The Author(s) 2014. This article is published with open access at Springerlink.com

\begin{abstract}
The rising speed of gas kick is an important parameter in well control operation. The position of the gas kick dictates the pressure at the casing shoe, which is usually the weakest point in the openhole section, and the wellhead pressure, which is one of the key factors affecting the blowout preventer and choke folder. In this research, we derived a rigorous model to estimate the rising speed of gas kick. Starting from the force analysis and mass conservation, we developed equations to calculate the forces exerting on the gas kick. With the mass of the gas kick, the rising speed of the gas kick is calculated. The effect of wellbore temperature profile on the rising of the gas kick is taken into account in the derivation. Before the development of this model, the estimation of gas kick position is commonly based on experience. In many cases, the experience alone is not good enough for well control. The proposed model provides a new approach with solid theoretical base to characterize the rising of gas kick in the hole. It makes the procedure of the well control simple and makes drilling engineers feel more comfortable to control the well. The new model can be combined with engineers experience to predict the downhole situation, shut-in casing pressure, and mud rate as a functions of position of gas kick. Any deviation from the forecast indicates accidents or downhole problems. Therefore, the proposed model is a valuable tool to diagnose the problems in well control.
\end{abstract}

K. Ling $(\bowtie) \cdot$ J. He $\cdot$ J. Ge $\cdot$ P. Pei

University of North Dakota, Grand Forks, TX, USA

e-mail: kegangling@yahoo.com

Z. Shen

Texas A\&M University, College Station, ND, USA
Keywords Gas kick · Well control · Kick migration speed

\begin{tabular}{|c|c|}
\hline \multicolumn{2}{|l|}{ Nomenclature } \\
\hline$A_{\text {cone base }}$ & $=$ Area of base of cone of gas column \\
\hline$A_{\text {cone surface }}$ & $\begin{array}{l}=\text { Characteristic area of the cone of gas } \\
\text { column }\end{array}$ \\
\hline$A_{\text {gas column base }}$ & $=$ Area of base of gas column \\
\hline$A_{\text {gas column flank }}$ & $=$ Surface area of flank of gas column \\
\hline$a$ & $=$ Acceleration \\
\hline$D_{1}$ & $=$ Drillpipe diameter \\
\hline$D_{2}$ & $=$ Wellbore diameter \\
\hline$E_{k}$ & $=$ Kinetic energy per unit volume \\
\hline$F_{1}$ & $=$ Fluid force behind the gas column \\
\hline$F_{2}$ & $=$ Fluid force in front of the gas column \\
\hline$F_{D 1}$ & $\begin{array}{l}=\text { Drag force on the flank of the gas } \\
\text { column }\end{array}$ \\
\hline$F_{D 2}$ & $\begin{array}{l}=\text { Drag force on the cone surface of gas } \\
\text { column }\end{array}$ \\
\hline$F_{D 2-V e r t}$ & $\begin{array}{l}=\text { Vertical drag force resulting from } \\
\text { drag force on the cone surface of gas } \\
\text { column }\end{array}$ \\
\hline$F_{G}$ & $=$ Gravitational force \\
\hline$F_{n e t}$ & $=$ Net force \\
\hline$f$ & $=$ Friction factor \\
\hline$f_{i}$ & $=$ Gas-mud interfacial friction factor \\
\hline$g$ & $=$ Gravitational acceleration \\
\hline$h_{\text {gas base }}$ & $=$ Location of base of gas column \\
\hline$h_{\text {gas center }}$ & $=$ Location of center of gas column \\
\hline$h_{\text {well }}$ & $=$ Well depth \\
\hline$K$ & $=$ Consistency index of mud \\
\hline$L_{\text {bottomhole-gas base }}$ & $\begin{array}{l}=\text { Distance between bottomehole and } \\
\text { base of gas column }\end{array}$ \\
\hline$L_{\text {gas cone }}$ & $=$ Height of cone part of gas kick \\
\hline
\end{tabular}




\begin{tabular}{|c|c|}
\hline$L_{\text {gas cylinder }}$ & $=$ Height of cylinder part of gas kick \\
\hline$L_{\text {gas kick }}$ & $=$ Height of gas kick \\
\hline$L_{\text {migrated }}$ & $=$ Gas migrated distance \\
\hline$L_{\text {wellhead-gas top }}$ & $\begin{array}{l}=\text { Distance between wellhead and top } \\
\text { of gas column }\end{array}$ \\
\hline$M$ & $=$ Molecular weight of gas \\
\hline$m_{g}$ & $=$ Mass of gas column \\
\hline$n$ & $=$ Flow-behavior index of mud \\
\hline$p_{1}$ & $=$ Pressure behind the gas column \\
\hline$p_{2}$ & $=$ Pressure in front of the gas column \\
\hline$p_{\text {casing }}$ & $=$ Casing pressure \\
\hline$p_{f}$ & $=$ Frictional pressure drop \\
\hline$p_{p}$ & $=$ Pore pressure \\
\hline$p_{\text {SIDP }}$ & $=$ Shut-in drillpipe pressure \\
\hline $\bar{p}_{\text {gas }}$ & $=$ Average pressure of gas column \\
\hline$R$ & $=$ Universal gas constant \\
\hline$T$ & $=$ Temperature at location \\
\hline$T_{B H}$ & $=$ Bottomhole temperature \\
\hline$u_{g}$ & $=$ Gas velocity \\
\hline$u_{m}$ & $=$ Mud velocity \\
\hline$V_{\text {gas cone }}$ & $=$ Volume of cone part of gas kick \\
\hline$V_{\text {gas cylinder }}$ & $=$ Volume of cylinder part of gas kick \\
\hline$V_{\text {gas kick }}$ & $=$ volume of gas kick at any location \\
\hline$V_{\text {gas kick,BH }}$ & $=$ Volume of gas kick at bottomhole \\
\hline$V_{M, \text { out }}$ & $=$ Volume of mud flow out the hole \\
\hline$V_{M, \text { in }}$ & $=$ Volume of mud flow into the hole \\
\hline$z$ & $=$ gas deviation factor \\
\hline$z_{\mathrm{BH}}$ & $=$ Gas deviation factor at bottomhole \\
\hline$\rho_{g}$ & $=$ Gas density \\
\hline$\rho_{g, \mathrm{BH}}$ & $=$ Gas density at botomhole \\
\hline$\rho_{m}$ & $=$ Mud density \\
\hline$\theta$ & $\begin{array}{l}=\text { Angle between } F_{D 2} \text { and vertical } \\
\text { direction }\end{array}$ \\
\hline$\theta_{300}$ & $\begin{array}{l}=\text { The } 300-\text { rpm dial reading in mud } \\
\text { viscometer }\end{array}$ \\
\hline$\theta_{600}$ & $\begin{array}{l}=\text { The } 600-\text {-rpm dial reading in mud } \\
\text { viscometer }\end{array}$ \\
\hline$\mu_{g}$ & $=$ Gas viscosity \\
\hline$\tau_{\mathrm{gm}}$ & $=$ Shear stress between gas and mud \\
\hline$\Delta t_{1}$ & $=1 \mathrm{st}$ time step \\
\hline
\end{tabular}

\section{Introduction}

The rising speed of gas kick is an important parameter in well control operation. The position of the gas kick dictates the pressure at the casing shoe, which is usually the weakest point in the openhole section, and the wellhead pressure, which is one of the key factors affecting the blowout preventer and choke folder. In many gas kick well control operations, the estimations of gas kick position are commonly based on experience. In many cases, the experience alone is not good enough for well control. A model with theoretical base to predict the gas kick rising speed is highly desired.

Many studies have been focused on gas-liquid two-phase flow in wellbore. Some researchers developed model to analyze two-phase flow in annuli during drilling. LeBlanc and Lewis (1968) built a mathematical model to calculate the backpressure during circulating gas kick out of well. In their model, the frictional pressure drop was ignored. Hoberock and Stanbery (1981a, b) combined different models to analyzed pressure distribution in wells during gas kicks assuming constant temperature along the annulus. Santos and Bourgoyne (1989) estimated pressure profile in wellbore for two-phase flow basing on flow regime. Van Slyke and Huang (1990) used a dynamic wellbore model to predict gas kick behavior in oil-based drilling mud. The mass of free gas changes with the temperature and pressure because the solution gas in oil-base mud varies along the wellbore. Johnson and White (1991) conducted experiment to examine gas migration rate in drilling mud in a $49-\mathrm{ft}$ long, 7.8-in ID inclinable flow loop. Skalle et al. (1991) studied gas rising velocity and its effect on bottomhole pressure (BHP) in a vertical well using experiment. Three empirical two-phase flow correlations were used to analyze the experimental data. Frank and Rolv (1991) ran full-scale kick experiments and studied the effect of different parameters on gas-rise velocity. Johnson and Steven (1993) investigated the gas migration velocities during gas kicks in deviated wells using the same facilities used by Johnson and White in 1991. Martins Lage et al. (1994) tested the gas kick migration in closed and open wells. Tarvin et al. (1994) analyzed data from test-well experiment and found that gas rises through drilling mud faster than the migration rates generally accepted in the drilling industry. Ashley et al. (1995) reviewed different gas migration velocity at different gas concentration. Choe (2001) developed a two-phase flow model to calculate pressure in annulus using flow regime. Nunes et al. (2002) used Beggs and Brill method to analyze gas kicks in deepwater well drilling. Yu et al. (2009) developed a mechanistic model for gas-liquid flow in upward vertical annuli. Flow regimes are applied in their model. Chirinos et al. (2011) proposed a simplified method to estimate peak casing pressure during managed pressure drilling well control.

\section{Methods to detect a kick}

It is crucial to detect a kick as the early beginning. Early detection can minimize the kick size and reduce the risk of blowout when controlling the well. Kick-detection equipment should be installed. The followings are important kick indications: 
1. An abrupt increase in penetration rate or drilling break

2. An increase in pump rate and a decrease in pump pressure

3. An increase in the mud return flow rate

4. Pit gains due to the increase in the mud return flow rate

5. An increase in drillstring weight

6. Gas cutting or salinity changes in the drilling fluid

7. Mud flows when pumps are off.

\section{Well control procedures to circulate out gas kick and kill the well}

When there is a kick, two methods are usually applied to circulate the kick out of the wellbore and keep the well under control. They are driller's method and wait and weight method. A thoroughly understanding of procedures of these two well control methods helps the development of governing equation for gas kick rising speed calculation. The basic principle of both methods is to keep BHP constant at the formation pressure. The driller's method differs from wait and weight method in the circulation number. Driller's method needs two circulations to circulate the kick out of hole and kill the well. Following steps are used in driller's method:

1. Shut in the well and get casing pressure and drillpipe pressure

2. Calculate the kill mud weight

3. Start up the pump by holding casing pressure constant

4. Pump old mud and circulate the kick out of hole while keeping drillpipe pressure constant

5. After circulating kick out of hole, pump kill mud; start up the pump by holding casing pressure constant

6. Hold casing pressure constant and pump kill mud until kill mud flow to the bit

7. Switch to constant drillpipe pressure and circulate kill mud until it flows out of the choke

8. Shut down pumps by holding casing pressure constant

9. Check casing pressure and drillpipe pressure to make sure both pressures are zero psi

10. If both pressures are zero psi, complete well control.

The procedure of wait and weight method is as follows:

1. Shut in the well and get casing pressure and drillpipe pressure

2. Calculate the kill mud weight and mix the kill mud

3. Start up the pump by holding casing pressure constant

4. Pump kill mud and circulate the kick out of hole while keeping BHP constant, manipulate the choke to make sure drillpipe pressure, and follow the pressure reduction schedule
5. Circulate kill mud until it flows out of the choke

6. Reduce pump speed while closing the choke

7. Shut down the pump

8. Check casing pressure and drillpipe pressure to make sure both pressures are zero psi

9. If both pressures are zero psi, complete well control.

\section{Gas kick rising speed in well control}

According to the procedure of driller's method, the old mud is pumped into the drillpipe to circulate the kick out of the hole, which occurs in the first circulation. Therefore, the mud in drillpipe and annulus has same properties. To analyze the gas kick rising speed during the circulation, following assumptions are made:

1. A volume of gas kick, $V_{g, \mathrm{BH}}$, entered into the bottomhole when the well is shut in

2. The compressibility of mud is neglected comparing with gas compressibility

3. Gas kick rises from the bottomhole to surface as a single column

4. There are two mud annuli between gas column and walls of wellbore and drillpipe due to the wettability effect. The thicknesses of these two annuli are very small comparing with the radius of the gas column

5. The temperature of gas column follows the temperature gradient in mud

6. Water base mud with negligible gas solubility

7. Drilling mud follows power-law model.

For a volume of gas kick, $V_{g, \mathrm{BH}}$, enters into the bottomhole, the volume of the gas kick equals the difference between the mud flow out of hole and into the hole.

$V_{\text {gas kick,BH }}=V_{M, \text { out }}-V_{M, \text { in }}$

where $V_{\text {gas }}$ kick,BH $=$ volume of gas kick at bottomhole, $V_{M \text {,out }}=$ volume of mud flow out the hole, $V_{M \text {,out }}=$ volume of mud flow out the hole, $V_{M \text {,in }}=$ volume of mud flow into the hole.

Since the time period between well shut in and starting pumping old mud to circulate the kick is very short, we can assume the migration of gas begin as the pump is started up. Now we analyze the rising speed of gas column at the beginning of first circulation. As old mud is pumped into the drillpipe, the gas kick migrates upward inside the annulus like a piston as shown in Fig. 1. At the time the gas kick begins to move upward, the height of gas kick is the sum of heights of cone part and cylinder part, which is expressed as

$L_{\text {gas kick }}=L_{\text {gas cone }}+L_{\text {gas cylinder }}$ 


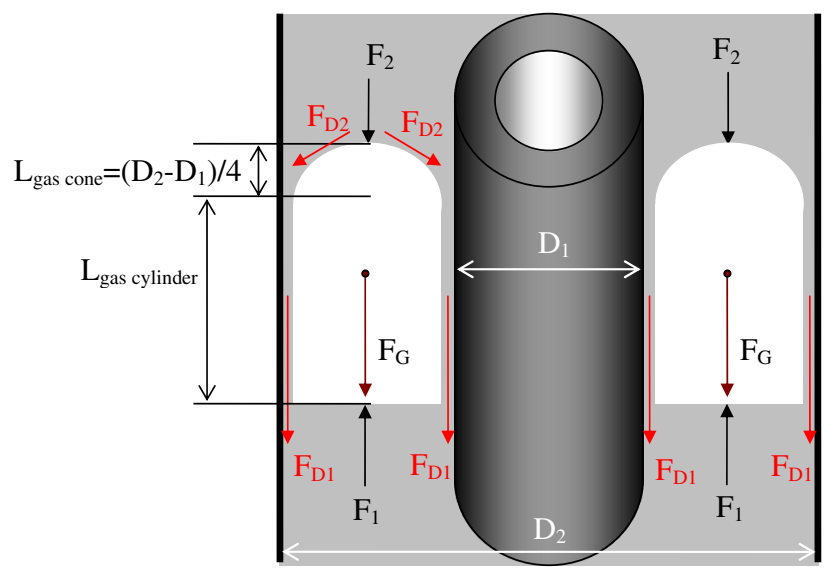

Fig. 1 Distribution of gas kick in the annuli

where $L_{\text {gas kick }}=$ height of gas kick, $L_{\text {gas cone }}=$ height of cone part of gas kick, $L_{\text {gas cylinder }}=$ height of cylinder part of gas kick.

Due to the effect of gas-mud interfacial tension, the height of cone should equal $\frac{D_{2}-D_{1}}{4}$ assuming the annuli between gas column and walls of wellbore and drillpipe are small and can be neglected. Therefore, the volume of gas kick can be expressed as

$$
\begin{aligned}
V_{\text {gas kick }}= & V_{\text {gas cone }}+V_{\text {gas cylinder }} \\
= & 2 \pi\left(\frac{D_{1}}{2}+\frac{D_{2}-D_{1}}{4}\right) \frac{\pi}{2} \frac{\left(D_{2}-D_{1}\right)^{2}}{16} \\
& +\pi \frac{D_{2}^{2}-D_{1}^{2}}{4} L_{\text {gas cylinder }} \\
= & \pi^{2}\left(\frac{D_{2}^{2}-D_{1}^{2}}{4}\right)\left(\frac{D_{2}+D_{1}}{16}\right)+\pi \frac{D_{2}^{2}-D_{1}^{2}}{4} L_{\text {gas cylinder }}
\end{aligned}
$$

where $V_{\text {gas }}$ kick $=$ volume of gas kick at any location, $V_{\text {gas cone }}=$ volume of cone part of gas kick, $\mathrm{V}_{\text {gas cylinder }}=$ volume of cylinder part of gas kick, $D_{1}=$ drillpipe diameter, $D_{2}=$ wellbore diameter.

Therefore, the height of gas cylinder can be estimated from gas kick volume, which is

$$
\begin{aligned}
L_{\text {gas cylinder }} & =\frac{V_{\text {gas kick }}-\pi^{2}\left(\frac{D_{2}^{2}-D_{1}^{2}}{4}\right)\left(\frac{D_{2}+D_{1}}{16}\right)}{\pi \frac{D_{2}^{2}-D_{1}^{2}}{4}} \\
& =\frac{V_{\text {gas kick }}}{\pi \frac{D_{2}^{2}-D_{1}^{2}}{4}}-\pi\left(\frac{D_{2}+D_{1}}{16}\right)
\end{aligned}
$$

As the gas column moves upward, the gas expands. According to Eq. (4), the shape of gas cone remains constant while the height of gas cylinder becomes longer due to gas expansion.

To estimate the rising velocity of gas kick, force analysis is required. Forces on gas column can be analyzed in two dimensions, horizontal and vertical directions. For the purpose of this study, horizontal forces are not considered. According to the U-tube theory, the pressure inside the drillpipe should be balanced by pressure in the annulus. When the old mud is pumped into the drillpipe, the gas column will move upward along the annulus. The gas column is subjected to five forces, the gravitational force, the drag force on the cone surface of gas column, the drag force on the flank of the gas column, the fluid forces in front of and behind the gas column. Because the forces in the vertical direction control the upward movement of gas kick, they are analyzed here. The net force in vertical direction is calculated by

$F_{\text {net }}=F_{1}-F_{2}-F_{D 1}-F_{D 2-\text { Vert }}-F_{G}$

or

$F_{\text {net }}=F_{1}-F_{2}-F_{D 1}-\int_{0^{\circ}}^{90^{\circ}} F_{D 2} \cos \theta \mathrm{d} \theta-F_{G}$

where $F_{\text {net }}=$ net force, $F_{G}=$ gravitational force, $F_{D 2}=$ drag force on the cone surface of gas column, $F_{D 2-\text { Vert }}=$ vertical drag force resulting from drag force on the cone surface of gas column, $F_{D 1}=$ drag force on the flank of the gas column, $F_{2}=$ fluid force in front of the gas column, $F_{1}=$ fluid force behind the gas column, $\theta=$ angle between $F_{D 2}$ and vertical direction.

The fluid force behind the gas column is

$F_{1}=p_{1} A_{\text {gas column base }}=\pi \frac{D_{2}^{2}-D_{1}^{2}}{4} p_{1}$

where $p_{1}=$ pressure below the gas column, $A_{\text {gas column base }}=$ area of base of gas column.

According to the basic principle in the driller's and engineer's methods, BHP is kept constant during the circulation, which means BHP always equals pore pressure. Therefore, the pressure below the gas column can be expressed in terms of pore pressure, frictional pressure drop, and pressure change due to potential energy change, which is

$p_{1}=p_{p}-\rho_{m} g L_{\text {bottomhole }- \text { gas base }}-p_{f}$

where $p_{p}=$ pore pressure, $\rho_{m}=$ mud density, $g=$ gravitational acceleration, $L_{\text {bottomhole-gas base }}=$ distance between bottomhole and base of gas column, $p_{f}=$ frictional pressure drop between bottomhole and base of gas column.

Pore pressure can be estimated from the shut-in drillpipe pressure and static hydraulic pressure due to drill mud, which is

$p_{p}=p_{\mathrm{SIDP}}+\rho_{m} \mathrm{gh}_{\mathrm{well}}$

where $p_{\text {SIDP }}=$ shut-in drillpipe pressure, $h_{\text {well }}=$ well depth. 
The frictional pressure drop depends on the flow regime. When the Reynolds number is less than 2,100, the flow is laminar; otherwise, it is turbulent flow. The Reynolds number is calculated through (Bourgoyne et al. 1986)

$N_{\mathrm{Re}}=\frac{109000 \rho_{m} u_{m}^{2-n}}{K}\left[\frac{0.0208\left(D_{2}-D_{1}\right)}{2+1 / n}\right]^{n}$

where

$K=\frac{510 \theta_{300}}{511^{n}}$

$n=3.32 \log \frac{\theta_{600}}{\theta_{300}}$

where $K=$ consistency index of mud, $n=$ flow-behavior index of mud, $u_{m}=$ mud velocity, $\theta_{300}=$ the 300 -rpm dial reading in mud viscometer, $\theta_{600}=$ the 600 -rpm dial reading in mud viscometer.

If the flow is laminar flow, the frictional pressure drop can be calculated by (Bourgoyne et al. 1986)

$$
\begin{aligned}
p_{f} & =\frac{\mathrm{d} p_{f}}{\mathrm{~d} h} L_{\text {bottomhole-gas base }} \\
& =\frac{K u_{m}^{n}\left(\frac{2+1 / n}{0.0208}\right)^{n}}{144000\left(D_{2}-D_{1}\right)^{1+n}} L_{\text {bottomhole-gas base }}
\end{aligned}
$$

If the flow is turbulent flow, the frictional pressure drop can be calculated by

$$
\begin{aligned}
p_{f} & =\frac{\mathrm{d} p_{f}}{\mathrm{~d} h} L_{\text {bottomhole-gas base }} \\
& =\frac{f \rho_{m} u_{m}^{2}}{21.1\left(D_{2}-D_{1}\right)} L_{\text {bottomhole-gas base }}
\end{aligned}
$$

where $f=$ friction factor.

The friction factor can be read from Fig. 2.

The fluid force in front of the gas column is

$F_{2}=p_{2} A_{\text {cone base }}=p_{2} A_{\text {gas column base }}=\pi \frac{D_{2}^{2}-D_{1}^{2}}{4} p_{2}$

where $p_{2}=$ pressure in front of the gas column, $A_{\text {cone base }}=$ area of base of cone of gas column, which equals area of base of gas column.

The pressure in front of the gas column can be expressed in terms of casing pressure, frictional pressure drop, and pressure change due to potential energy change, which is

$p_{2}=p_{\text {casing }}+\rho_{m} g L_{\text {wellhead }- \text { gas top }}-p_{f}$

where $p_{\text {casing }}=$ casing pressure, $L_{\text {wellhead-gas top }}=$ distance between wellhead and top of gas column.

Casing pressure is readily available during circulation. The calculation of frictional pressure drop is akin to the frictional pressure drop between bottomhole and base of gas column. In case of laminar flow, the frictional pressure drop is
Fig. 2 Friction factor for power-law fluid model, after Bourgoyne et al. (1986)

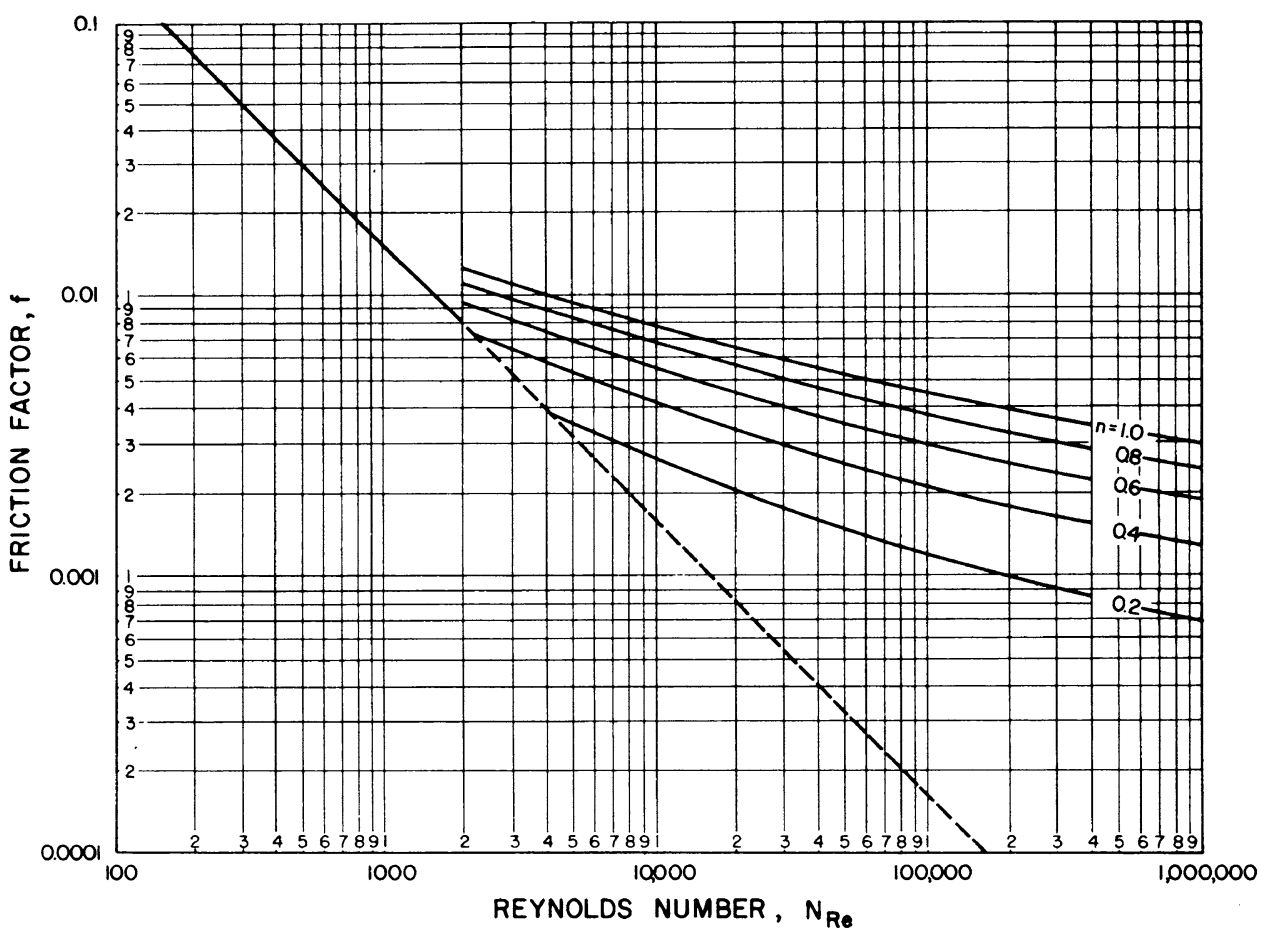




$$
\begin{aligned}
p_{f} & =\frac{\mathrm{d} p_{f}}{\mathrm{~d} h} L_{\text {wellhead-gas top }} \\
& =\frac{K u_{m}^{n}\left(\frac{2+1 / n}{0.0208}\right)^{n}}{144000\left(D_{2}-D_{1}\right)^{1+n}} L_{\text {wellhead-gas top }}
\end{aligned}
$$

If the flow is turbulent flow, the frictional pressure drop can be calculated by

$p_{f}=\frac{\mathrm{d} p_{f}}{\mathrm{~d} h} L_{\text {wellhead-gas top }}=\frac{f \rho_{m} u_{m}^{2}}{21.1\left(D_{2}-D_{1}\right)} L_{\text {wellhead-gas top }}$

Again, Reynolds number is calculated from Eq. (9) and friction factor is read from Fig. 2 .

The drag force on the flank of the gas column can be derived according to the flow regime: laminar and turbulent flow conditions. When gas column moves upward along the annulus, the drag force on the flank of the gas column is

$F_{D 1}=A_{\text {gas column flank }} \tau_{\mathrm{gm}}=\pi\left(D_{1}+D_{2}\right) L_{\mathrm{gas} \text { cylinder }} \tau_{\mathrm{gm}}$

where $A_{\text {gas column flank }}=$ surface area of flank of gas column, $\tau_{\mathrm{gm}}=$ shear stress between gas and mud.

Shear stress between gas and mud is calculated through (Taitel 1995)

$\tau_{\mathrm{gm}}=\frac{f_{i} \rho_{g} u_{g}^{2}}{2}$

where $f_{i}=$ gas-mud interfacial friction factor, $u_{g}=$ gas velocity, $\rho_{g}=$ gas density.

Gas-mud interfacial friction factor is calculated by

$f_{i}=\mathrm{CN}_{\mathrm{Re}}^{-n}$

where $C=16$ and $n=1.0$ for laminar flow, and $C=0.046$ and $n=0.2$ for turbulent flow. If $f_{i}$ from Eq. (20) is larger than $0.014, f_{i}=0.014$ should be used.

Reynolds number is calculated by

$N_{\mathrm{Re}}=\frac{\rho_{g} u_{g}\left(D_{2}-D_{1}\right)}{\mu_{g}}$

where $\mu_{g}=$ gas viscosity.

The drag force on the cone surface, $F_{D 2}$, can be estimated by Ling's (2010) method. In Fig. 1, the cone of gas column experiences a drag force resulting from the viscous mud flow around the cone surface. The magnitude of drag force depends on the flow regime, laminar, or turbulent flow. For laminar flow, the drag force is calculated from Stokes law. Stokes law has shown that for creeping flow (Castleman 1926), the drag force is related to the gas cone velocity through the fluid by:

$$
\begin{aligned}
F_{D 2} & =3 \pi\left(\frac{D_{2}-D_{1}}{2}\right) \frac{\pi\left(\frac{D_{2}-D_{1}}{4}\right) 2 \pi\left(\frac{D_{1}}{2}+\frac{D_{2}-D_{1}}{4}\right)}{4 \pi\left(\frac{D_{2}-D_{1}}{4}\right)^{2}} \mu_{g} u_{g} \\
& =\frac{3}{4} \pi^{2}\left(D_{2}+D_{1}\right) \mu_{g} u_{g} .
\end{aligned}
$$

Decomposing the drag force on the cone surface, we obtain vertical direction force, which is

$$
\begin{aligned}
F_{D 2-\text { Vert }}= & \int_{0^{\circ}}^{90^{\circ}} F_{D 2} \cos \theta \mathrm{d} \theta=F_{D 2}\left[\sin \left(90^{\circ}\right)-\sin \left(0^{\circ}\right)\right] \\
& =F_{D 2}=\frac{3}{4} \pi^{2}\left(D_{2}+D_{1}\right) \mu_{g} u_{g} .
\end{aligned}
$$

Equation (23) is found to give acceptable accuracy for Reynolds numbers below 0.1. For Reynolds numbers greater than 0.1 , the drag force needs to be estimated using friction factor. The friction factor is defined by:

$f=\frac{F_{D 2}}{A_{\text {cone surface }} E_{k}}$

where $A_{\text {cone surface }}=$ characteristic area of the cone of gas column, $E_{k}=$ kinetic energy per unit volume.

Then, the drag force can be expressed as:

$F_{D 2}=f A_{\text {cone surface }} E_{k}$

The characteristic area of the cone of gas column is given by:

$$
\begin{aligned}
A_{\text {cone surface }} & =\frac{1}{4} \pi\left(\frac{D_{2}-D_{1}}{4}\right) 2 \pi\left(\frac{D_{2}+D_{1}}{4}\right) \\
& =\frac{\pi^{2}}{32}\left(D_{2}^{2}-D_{1}^{2}\right)
\end{aligned}
$$

The kinetic energy per unit volume is given by:

$E_{k}=\frac{\rho_{g} u_{g}^{2}}{2}$

The friction factor $f$ can be calculated by Eq. (20). If $f_{i}$ from Eq. (20) is larger than $0.014, f_{i}=0.014$ should be used.

The gravity force resulting from the gas column is expressed as

$F_{G}=\rho_{g, \mathrm{BH}} g V_{\text {gas kick,BH }}$

where

$\rho_{\mathrm{g}, \mathrm{BH}}=\frac{p_{p} M}{z \mathrm{RT}_{\mathrm{BH}}}$

$M=$ molecular weight of gas, $R=$ universal gas constant, $z=$ gas deviation factor, $T_{\mathrm{BH}}=$ bottomhole temperature, $\rho_{g, \mathrm{BH}}=$ gas density at bottomhole.

The molecular weight can be calculated from gasspecific gravity. Gas-specific gravity can be calculated from shut-in drillpipe pressure, shut-in casing pressure, mud density, and pit gain, or from offset well gas 
property. Bottomhole temperature and temperature at any depth can be estimated using regional temperature gradient. Gravity force of gas column is constant during the gas migration.

Substituting Eqs. (6), (14), (18), (23), and (28) into (5), we have

$$
\begin{aligned}
F_{\text {net }}= & \pi \frac{D_{2}^{2}-D_{1}^{2}}{4} p_{1}-\pi \frac{D_{2}^{2}-D_{1}^{2}}{4} p_{2} \\
& -\pi\left(D_{1}+D_{2}\right) L_{\text {gas cylinder }} \tau_{\text {gm }}-\frac{3}{4} \pi^{2}\left(D_{2}+D_{1}\right) \mu_{g} u_{g} \\
& -\rho_{g, \mathrm{BH}} g V_{\text {gas kick,BH }}=\pi\left(\frac{D_{2}^{2}-D_{1}^{2}}{4}\right)\left(p_{1}-p_{2}\right) \\
& -\pi\left(D_{2}+D_{1}\right) u_{g}\left[L_{\text {gas cylinder }} \frac{8}{N_{\mathrm{Re}}} \rho_{g} u_{g}+\frac{3}{4} \pi \mu_{g}\right] \\
& -\rho_{g, \mathrm{BH}} g V_{\text {gas kick }, \mathrm{BH}}
\end{aligned}
$$

for laminar flow.

Substituting Eqs. (6), (14), (18), (25), and (28) into (5), we have

$$
\begin{aligned}
F_{\text {net }}= & \pi \frac{D_{2}^{2}-D_{1}^{2}}{4} p_{1}-\pi \frac{D_{2}^{2}-D_{1}^{2}}{4} p_{2} \\
& -\pi\left(D_{1}+D_{2}\right) L_{\text {gas cylinder }} \tau_{\mathrm{gm}}-f A_{\text {cone surface }} E_{k} \\
& -\rho_{g, \mathrm{BH}} g V_{\mathrm{gas} \text { kick }, \mathrm{BH}} \\
= & \pi\left(\frac{D_{2}^{2}-D_{1}^{2}}{4}\right)\left(p_{1}-p_{2}\right)-\pi\left(D_{2}+D_{1}\right) L_{\mathrm{gas} \text { cylinder }} \frac{\frac{0.046}{N_{\mathrm{re}}^{0.2}} \rho_{g} u_{g}^{2}}{2} \\
& -f \frac{\pi^{2}}{32}\left(D_{2}^{2}-D_{1}^{2}\right) \frac{\rho_{m} u_{g}^{2}}{2}-\rho_{g, \mathrm{BH}} g V_{\text {gas kick,BH }}
\end{aligned}
$$

for turbulent flow.

With the calculated net force, the acceleration of gas column can be calculated through

$a=\frac{F_{\text {net }}}{m_{g}}=\frac{F_{\text {net }}}{\rho_{g, \mathrm{BH}} V_{\text {gas kick,BH }}}$

where $a=$ acceleration, $m_{g}=$ mass of gas column.

Therefore, substituting Eqs. (30) and (31) into (32) gives the governing equations for accelerations of gas column under laminar and turbulent flows, respectively.

$a=\frac{\pi\left(\frac{D_{2}^{2}-D_{1}^{2}}{4}\right)\left(p_{1}-p_{2}\right)-\pi\left(D_{2}+D_{1}\right) u_{g}\left[L_{\text {gas cylinder }} \frac{8}{N_{\mathrm{Re}}} \rho_{g} u_{g}+\frac{3}{4} \pi \mu_{g}\right]}{\rho_{g, \mathrm{BH}} V_{\text {gas kick, BH }}}-g$

and

$a=\frac{\pi\left(\frac{D_{2}^{2}-D_{1}^{2}}{4}\right)\left(p_{1}-p_{2}\right)-\pi\left(D_{2}+D_{1}\right) L_{\text {gas cylinder }} \frac{\frac{0.046}{N_{\text {re }}} \rho_{g} u_{g}^{2}}{2}-f \frac{\pi^{2}}{32}\left(D_{2}^{2}-D_{1}^{2}\right) \frac{\rho_{m} u_{g}^{2}}{2}}{\rho_{g, \mathrm{BH}} V_{\text {gas kick } \mathrm{BH}}}-g$

\section{Calculation procedure}

The calculation of gas column migrating up the annuli can be broken into the following steps:

1) Calculate the acceleration of gas column when it starts to migrate; at this moment, there is no drag force, so Eqs. (33) and (34) reduce to

$a=\frac{\pi\left(\frac{D_{2}^{2}-D_{1}^{2}}{4}\right)\left(p_{1}-p_{2}\right)}{\rho_{g, \mathrm{BH}} V_{\text {gas kick,BH }}}-g$

2) Select a small 1 st time step, $\Delta t_{1}$, and calculate the velocity of gas column at the end of 1 st time step by

$u_{g}=a \Delta t_{1}$

3) Calculate the migrated distance, $L_{\text {migrated }}$, by

$L_{\text {migrated }}=\frac{1}{2} a \Delta t_{1}^{2}$

4) Calculate the location of base of gas column, $h_{\text {gas base }}$, by

$h_{\text {gas base }}=h_{\text {well }}-L_{\text {migrated }}$

Table 1 Input data for gas kick migration calculation

\begin{tabular}{lll}
\hline Molecular weight of gas & 20 & $\mathrm{lb} / \mathrm{lb}-\mathrm{mole}$ \\
Gas specific gravity & 0.69 & $\mathrm{air}=1.0$ \\
Well depth at kick occur & 9,975 & $\mathrm{ft}$ \\
Wellbore diameter & 8.5 & $\mathrm{in}$. \\
Drillpipe length & 9,445 & $\mathrm{ft}$ \\
Drillpipe diameter (OD) & 4.5 & $\mathrm{in}$. \\
Drill collar length & 530 & $\mathrm{ft}$ \\
Drill collar diameter (OD) & 6.25 & $\mathrm{in}$. \\
Shut-in drillpipe pressure & 275 & $\mathrm{psi}$ \\
Shut-in casing pressure & 448 & $\mathrm{psi}$ \\
Bottomhole temperature & 180 & ${ }^{\circ} \mathrm{F}$ \\
Temperature gradient & 1.1 & ${ }^{\circ} \mathrm{F} / 100 \mathrm{ft}$ \\
Pit gains or kick volume at bottomhole & 13.6 & $\mathrm{bbl}$ \\
Mud density & 11.7 & $\mathrm{lbm} / \mathrm{gal}^{2}$ \\
The 300-rpm dial reading in mud viscometer & 29 & $\mathrm{lbf} / 100 \mathrm{ft}^{2}$ \\
The 600-rpm dial reading in mud viscometer & 46 & $\mathrm{lbf} / 100 \mathrm{ft}{ }^{2}$ \\
Consistency index of mud & 234 & $\mathrm{cp}$ \\
Flow-behavior index of mud & 0.67 & \\
Mud pressure gradient & 0.608 & $\mathrm{psi} / \mathrm{ft}^{2}$ \\
Mass of kick & 1,304 & $\mathrm{lbm}$ \\
Gravitational acceleration & 31.174 & $\mathrm{ft} / \mathrm{s}^{2}$ \\
Bottomhole pressure & 6,338 & $\mathrm{psi}$ \\
Kick density at bottomhole & 17.08 & $\mathrm{lbm} / \mathrm{ft}^{3}$ \\
\hline & &
\end{tabular}

Molecular weight of gas

Gas specific gravity

Well depth at kick occur

ellbore diameter

Drillpipe length

Drillpipe diameter (OD)

Drill collar length

Drill collar diameter (OD)

Bottomhole temperature

Mud density

Consistency index of mud

low-behavior index of mu

Mud pressure gradien

Gravitational acceleration

Kick density at bottomhole

(1) 
5) Assuming a new gas volume, which is larger than gas volume at bottomhole; calculate the height of gas column, $h_{\text {gas kick }}$ through Eq. (3)

6) Calculate the location of center of gas column $h_{\text {gas center }}$, by

$h_{\text {gas center }}=h_{\text {gas base }}-\frac{L_{\text {gas kick }}}{2}$

7) Calculate the average pressure of gas column, $\bar{p}_{\text {gas }}$

8) Using real gas law, calculate the volume of gas kick at new location, which is

$V_{\text {gas kick }}=\frac{z_{\mathrm{BH}} T_{\mathrm{BH}} \bar{p}_{\text {gas }}}{z T p_{p} V_{\text {gas kick,BH }}}$

where $T=$ temperature at location, $z_{\mathrm{BH}}=$ gas deviation factor at bottomhole, $\Delta t_{1}=1$ st time step, $L_{\text {migrated }}=$ gas migrated distance, $h_{\text {gas base }}=$ location of base of gas column, $h_{\text {gas }}$ center $=$ location of center of gas column, $\bar{p}_{\text {gas }}=$ average pressure of gas column.

9) If calculated gas volume is different from assumed volume in Step 5, repeat Steps 5 through 8 until a converged volume is obtained

10) With the gas column location after 1st time step, we can calculate the acceleration of gas column using Eq. (33) or (34)

11) Select 2 nd time step and calculate the velocity and migrated distance at the end of 2nd time step

12) Repeat Steps 4 through 11 until base of gas column migrates to the surface

\section{Case study to illustrate the validation and application of model}

Field data from a gas kick detection and control in a well in Southeast Asia were used to verify the model. A kick was detected when the well was drilled to a depth of 9,975 ft. The well was shut in; the influx was contained and further entry of formation fluid was prevented. The pit gains were 13.6 bbl when the well was shut in. Shut-in casing and drillpipe pressures were recorded. The driller's method was used to circulate the kick out the hole and control the well. Table 1 shows the key parameters used in the calculations.

The calculated time for gas migrating to wellhead is $123.1 \mathrm{~min}$. Field observed that it takes $129.3 \mathrm{~min}$ for gas migration. The absolute error is $-6.2 \mathrm{~min}$ and the relative error is $-4.8 \%$. The errors can be results of irregular borehole, inaccurate temperature profile in wellbore, inaccurate measurement of pit gains, variation of mud properties along the wellbore, inaccurate kick properties, and any deviation from the aforementioned assumptions. Therefore, the model gives reasonable results.

A computer program is coded to calculate the rising of gas kick. Thus, the calculation can be done within acceptable time period after the well is shut in. Then, the calculation can provide a forecast of gas kick location versus circulating time for circulating kick out of hole operation. The real-time data during well control can be compared with the predicted values. Any deviation from forecast could be an indication of downhole problem. The proposed method can be combined with engineers experience to predict the downhole situation, shut-in casing pressure, and mud rate as functions of position of gas kick. Therefore, the new model is a valuable tool in well control.

\section{Conclusions}

Following conclusions can be drawn from this study:

The governing equation to estimate the gas kick migration velocity in the annuli has been developed.

The procedure to calculate the migration of gas kick from bottomhole to surface has been proposed.

Differences between forecast values and real-time data in well control could be signs of downhole problems.

Acknowledgments This paper was firstly presented at the SPE Middle East Unconventional Gas Conference \& Exhibition held in Muscat, Sultanate of Oman on January 28-30, 2013. The authors thank Society of Petroleum Engineers (SPE) in allowing us to publish this paper with Journal of Petroleum Exploration and Production Technology. The authors are grateful to The Petroleum Engineering Department in University of North Dakota. This research is supported in part by the U.S. Department of Energy (DOE) under award number DE-FC26-08NT0005643.

Open Access This article is distributed under the terms of the Creative Commons Attribution License which permits any use, distribution, and reproduction in any medium, provided the original author(s) and the source are credited.

\section{References}

Ashley J, Ian RC, Tim B, Dominic M (1995) Gas migration: fast, slow or stopped, SPE 29342, SPE/IADC drilling conference, Amsterdam, Netherlands, 28 Feb-2 March 1995

Bourgoyne TA, Chenevert EM, Millhein KK, Young SF (1986) Applied drilling engineering. Textbook Series, SPE, Richardson

Castleman RA (1926) The resistance to the steady motion of small spheres in fluids. In: National advisory committee for aeronautics, Technical note no. 231, Washington, DC, February

Chirinos JE, Smith JR, Bourgoyne D (2011) A simplified method to estimate peak casing pressure during mpd well control, SPE 
147496, SPE annual technical conference and exhibition, Denver, Colorado, USA, 30 Oct-2 Nov 2011

Choe J (2001) Advanced two-phase well control analysis. J Canad Petrol Technol 40(11):39-47

Frank H, Rolv R (1991) Analysis of gas-rise velocities from full-scale kick experiments, SPE 24580, SPE annual technical conference and exhibition. Washington, DC, 4-7 Oct 1992

Hoberock LL, Stanbery SR (1981a) Pressure dynamics in wells during gas kicks: part 1 - component models and results. J Petrol Technol 33(8):1357-1366

Hoberock LL, Stanbery SR (1981b) Pressure dynamics in wells during gas kicks: part 2-component models and results. J Petrol Technol 33(8):1367-1378

Johnson AB, Steven C (1993) Gas migration velocities during gas kicks in deviated wells, SPE 26331, SPE annual technical conference and exhibition, Houston, Texas, 3-6 Oct 1993

Johnson AB, White DB (1991) Gas-rise velocities during kicks. SPE Drill Eng 6(4):257-263

LeBlanc JL, Lewis RL (1968) A mathematical model of a gas kick. J Petrol Technol 20(8):888-898

Ling K (2010) Gas viscosity at high pressures and high temperatures, Ph.D. dissertation, Texas A\&M University, College Station

Martins Lage ACV, Nakagawa EY, Cordovil AGDP (1994) Experimental tests for gas kick migration analysis, SPE 26953, SPE Latin America/Caribbean petroleum engineering conference, Buenos Aires, Argentina, 27-29 April 1994

Nunes JOL, Bannwart AC, Ribeiro PR (2002) Mathematical modeling of gas kicks in deep water scenario, SPE 77253,
IADC/SPE Asia Pacific Drilling Technology, Jakarta, Indonesia, 8-11 Sept 2002

Santos OL, Bourgoyne Jr AT (1989) Estimation of pressure peaks occurring when diverting shallow gas, SPE 19559, SPE annual technical conference and exhibition, San Antonio, Texas, 8-11 Oct 1989

Skalle P, Podio AL, Tronvoll J (1991) Experimental study of gas rise velocity and its effect on bottomhole pressure in a vertical well, SPE 23160, Offshore Europe, Aberdeen, United Kingdom, 3-6 Sept 1991

Taitel Y, Barnea D, Brill JP (1995) Stratified three phase flow in pipes. Int J Multi Flow 21(1):53-60

Tarvin JA, Hamilton AP, Gaynord PJ, Lindsay GD (1994) Gas rises rapidly through drilling mud, SPE 27499, SPE/IADC drilling conference, Dallas, Texas, 15-18 Feb 1994

Van Slyke DC, Huang ETS (1990) Predicting gas kick behavior in oil-based drilling fluids using a pc-based dynamic wellbore model, SPE 19972, SPE/IADC drilling conference, Houston, Texas, 27 Feb-2 March 1990

Yu TT, Zhang HQ, Li MX, Sarica C (2009) A mechanistic model for gas/liquid flow in upward vertical annuli, SPE 124181, SPE annual technical conference and exhibition, New Orleans, Louisiana, 4-7 Oct 2009 